\title{
Mechanically Increased Right Ventricular Afterload Alters Left Ventricular Configuration, Not Contractility, in Neonatal Lambs
}

\author{
JAY M. MILSTEIN AND STANTON A. GLANTZ \\ Division of Neonatology. Department of Pediatrics, University of California, Davis, California 95616 [J.M.M.]; \\ and Cardiovascular Research Institute, Department of Medicine. University of California. San Francisco, \\ California 94143 [S.A.G.]
}

\begin{abstract}
Left ventricular dysfunction has been observed in human infants with pulmonary hypertension. The purpose of this study was to establish whether mechanically increased right ventricular afterload alters left ventricular performance by altering its contractility, configuration, or both. Six neonatal 3- to 7-d-old lambs were acutely instrumented with micromanometer-tipped catheters and two pairs of ultrasonic crystals to measure left ventricular pressure and anterior-posterior and septal-free wall dimensions. The product of these two dimensions, denoted left ventricular area, was used as an index of left ventricular volume. Two levels of mechanically increased right ventricular afterload were induced with a closed pericardium under three levels of left ventricular preload produced by whole-blood transfusions. Four brief increases in left ventricular afterload were induced by constricting the aorta under each right ventricular afterload and preload condition. Using multiple linear regression, we found that the slope of the end-systolic pressure-area relationship, an index of contractility, was unchanged $[0.90 \pm 0.11 \mathrm{~mm} \mathrm{Hg} /$ $\left.\mathrm{mm}^{2}(\mathrm{SEM})\right]$, and stroke area $\left(65.8 \pm 7 \mathrm{~mm}^{2}\right)$ and cardiac output (the product of stroke area and heart rate) (13400 $\pm 1660 \mathrm{~mm}^{2} / \mathrm{min}$ ) were maintained. However, the area intercept of the pressure-area line at zero pressure $(499 \pm$ $13 \mathrm{~mm}^{2}$ ) shifted significantly to the left in the presence of both levels of increased right ventricular afterload (by $-39.2 \pm 13$ and $-76.2 \pm 15 \mathrm{~mm}^{2}$, respectively). Mechanically increased right ventricular afterload alters left ventricular configuration and causes a shift in the operating volume (area) range of the ventricle with no change in contractility in 3- to 7-d-old lambs. (Pediatr Res 33: 359364,1993 )
\end{abstract}

\section{Abbreviations}

$\mathrm{LV} \mathrm{dP} / \mathrm{dt}_{\max }$, maximum derivative left ventricular pressure $E_{\max }$, slope of end-systolic pressure-area relationship

$A_{d}$, area-axis intercept of end-systolic pressure-area relationship at zero pressure

LVEDP. left ventricular end-diastolic pressure

EDV, end-diastolic volume

Tremendous changes occur in the cardiovascular system during the transition from fetus to neonate. Fetal myocardium is

Received May 19. 1992: accepted December 9. 1992.

Correspondence and reprint requests: Jay M. Milstein. Division of Neonatology. Department of Pediatrics. TB 193. University of California, Davis, Davis, CA 95616.

Supported by National Heart, Lung and Blood Institute grant HL-25869. structurally and functionally immature compared with adult myocardium $(1,2)$, yet the resting indices of fetal myocardial performance are relatively high compared with those of the adult $(3,4)$. Because the newborn heart is already functioning near maximum contractility with little further reserve (5-9), direct ventricular interaction may play a more important role in allowing the left ventricle to respond to changes in loading conditions than it does in adults. The intraventricular septum is more compliant in neonates than in fetuses, increasing the potential for direct mechanical interaction between the right and left heart (10). Some infants with persistent pulmonary hypertension of the newborn exhibit left ventricular dysfunction (11-14). Similarly, adults with acute pulmonary hypertension secondary to acute respiratory failure or cor pulmonale secondary to chronic lung disease have associated left ventricular dysfunction (15-17). Ventricular interaction may be partially responsible for this association (18-21). The purpose of this study was to establish whether mechanically increased right ventricular afterload alters left ventricular performance by altering its contractility, configuration (via direct ventricular interaction), or both in the neonate.

In a previous study, we demonstrated that mechanically increased right ventricular afterload diminishes left ventricular performance based on simultaneous changes in systemic blood flow and $\mathrm{LV} \mathrm{dP} / \mathrm{dt}_{\max }(22)$. In contrast, when comparable increased right ventricular afterload was induced with alveolar hypoxia, systemic blood flow and $\mathrm{LV} \mathrm{dP} / \mathrm{dt}_{\max }$ increased. These changes could be blocked with propranolol, suggesting that they were mediated via catecholamine release (22). Inasmuch as we did not measure dimensions in our earlier work, we could not determine whether there had been a change in left ventricular contractility or filling, and we could not differentiate the relative roles of series and direct ventricular interaction.

To address directly whether changes in left ventricular dimensions and shapes associated with changes in right ventricular afterload could account for these changes in left ventricular function, we instrumented neonatal lambs between 3 and $7 \mathrm{~d}$ of age with micromanometer-tipped catheters and ultrasonic crystals to measure left ventricular pressure and midventricular anterior-posterior and septal-free wall dimensions and then mechanically increased right ventricular afterload. We took the product of these two dimensions, denoted the left ventricular minor axis area, as a measure of left ventricular size (23). The $\mathrm{E}_{\max }$, an index of contractility (9), did not change. However, the $\mathrm{A}_{d}$ shifted to the left in response to increased right ventricular afterload. The stroke areas did not change. These findings are compatible with a change in left ventricular configuration and a shift in the operating volume range of the ventricle with no change in contractility. In the neonate, as in the adult (24), series ventricular interaction plays a greater role than direct ventricular interaction in determining left ventricular systolic ventricular 
function in response to changes in right ventricular loading conditions.

\section{MATERIALS AND METHODS}

Experimental Preparation. Six healthy neonatal lambs between 3 and 7 days of age were blindfolded for calming and acutely anesthetized with i.v. $\alpha$-chloralose $(50 \mathrm{mg} / \mathrm{kg}$ in sodium borate solution) via a femoral venous catheter placed under local anesthesia. After intubation, the animals were ventilated with a Harvard animal ventilator. Arterial blood gases were maintained in nonhypoxic ranges $\left[\mathrm{pH}, 7.35\right.$ to 7.45 ; arterial $\mathrm{O}_{2}$ pressure, 13.06 to $33.325 \mathrm{kPa}$ (98 to 250 torr); arterial $\mathrm{CO}_{2}$ pressure, 4.39 to $6.26 \mathrm{kPa}$ (33 to 47 torr)] by adjusting the ventilator and administering sodium bicarbonate. After a left thoracotomy, the pericardium was opened across the base along the course of the main pulmonary artery to expose the great vessels and ductus arteriosus. The ductus arteriosus was ligated. The lambs were then given lidocaine systemically $(1 \mathrm{mg} / \mathrm{kg})$ to prevent arrhythmias, and, after gentle manual compression of the heart to reduce filling, the apex of the heart was popped out of the pericardial sac through the small opening across the base.

A mid-ventricular short-axis plane was visualized approximately half the distance from the apex to the base. The interventricular grooves were identified, and the free wall was visually divided into thirds. A pair of 6-mm hemispheric ultrasonic piezoelectric crystals $(25)$ were then aligned in the area of the anterior and posterior thirds to measure the anterior-posterior dimension with a sonomicrometer (Triton Technology, Inc., San Diego, CA). These crystals were then sewn to their respective epicardial surfaces. A $2.5-\mathrm{mm}$ cylindrical crystal was tunneled into the interventricular septum along the same minor axis plane, using a long plastic sleeve as an introducer, along a 19-gauge needle track placed to the left of the interventricular groove and below the juncture of the left anterior descending coronary artery and the first major diagonal branch. The final hemispheric crystal was then aligned along the middle or lateral third of the free wall of the left ventricle to measure the septal-free wall dimension. We took the product of the anterior-posterior and septal-free wall dimensions as a measure of left ventricular size, denoted ventricular area. This product accurately reflects volume changes in response to the interventions we studied (23).

After an additional dose of lidocaine $(1 \mathrm{mg} / \mathrm{kg})$, the heart was gently compressed again and replaced in the relatively intact pericardial sac. The incision across the base of the pericardium was left open, but the pericardial sac still enclosed the heart to maintain direct ventricular interactions (26). Two cuffed vascular occluders were placed around the main pulmonary artery and the descending aorta to control right and left ventricular afterloads, and an electromagnetic transducer (Statham, Oxnard, CA) was placed on the ascending aorta to measure flow. Finally, Millar micromanometer-tipped catheters (Millar Instruments Inc., Houston, TX) were placed retrograde into the right ventricle via the main pulmonary artery and into the left ventricle and ascending aorta via the carotid artery to measure right ventricular, left ventricular, and aortic pressures, respectively.

All animal experimentation was performed with the highest standards of humane care in accord with the NIH Guide for the Care and Use of Laboratory Animals.

Data acquisition and experimental protocol. Two levels of acutely increased right ventricular afterload were induced under baseline loading conditions as well as under two additional loading conditions generated by two transfusions of adult ewe whole blood $(10 \mathrm{~mL} / \mathrm{kg})$. Four brief, sustained aortic constrictions were induced under each right ventricular afterload and loading condition with return to baseline between each aortic occlusion to generate several distinctly different end-systolic pressure-area points for subsequent analysis. To prevent reflex bradycardia during these occlusions, the two vagus nerve trunks pre- viously isolated during the carotid artery dissection were irrigated with lidocaine before data acquisition.

The analog signals were recorded on a multichannel strip-chart recorder as well as an FM recorder (Honeywell $5600 \mathrm{C}$, Honeywell Inc., Pleasantville, NY). The recordings were then digitized at $250 \mathrm{~Hz}$ using an analog-to-digital converter and pressure-area plots generated on a DEC PDP-11/70 computer (Digital Equipment Corporation, Maynard, MA). LV dP/dt was estimated from the digitized pressure signal using central differences. Enddiastole was defined as the time of the peak of the R-wave on the electrocardiogram, and end-systole was defined as the time of minimum $\mathrm{LV} \mathrm{dP} / \mathrm{dt}$.

We plotted pressure-area loops at several different levels of afterload and used these data to define the end-systolic pressurearea (i.e. volume) relationship by drawing a straight line through the data by visual inspection to come as near as possible to the upper left corner of the pressure-area loops. The slope of this line is $E_{\max }$, and the area-axis intercept is $A_{d}$.

Statistical methods. Data were analyzed using a multipleregression implementation of a repeated-measures analysis of variance (27). The following equation was used in the regression analysis:

$$
\mathrm{y}=\mathrm{b}_{0}+\mathrm{b}_{\mathrm{Vb}} \mathrm{V}_{\mathrm{b}}+\mathrm{b}_{\mathrm{V}_{\mathrm{c}}} \mathrm{V}_{\mathrm{c}}+\mathrm{b}_{\mathrm{Cl}} \mathrm{C}_{1}+\mathrm{b}_{\mathrm{CII}} \mathrm{C}_{\mathrm{II}}+\sum \mathrm{b}_{\mathrm{Li}} \mathrm{L}_{\mathrm{i}}
$$

The dependent variables $(y)$ were maximum right ventricular pressure, heart rate, LVEDP and maximum pressures, $\mathrm{dP} / \mathrm{dt}_{\max }$, end-diastolic and end-systolic anterior-posterior and septal-free diameters and areas, stroke areas, cardiac outputs, $\mathrm{E}_{\max }$, and $\mathrm{A}_{\mathrm{d}}$.

Each dependent variable (y) observed in any given lamb under any set of experimental conditions is modeled as the sum of the average value across all lambs under control conditions $\left(b_{0}\right)$, plus the effect of the volume load $\left(\mathrm{V}_{\mathrm{i}}\right)$, the kind of constriction used to acutely load the heart $\left(\mathrm{C}_{\mathrm{i}}\right)$, and different mean responses in different lambs $\left(\mathrm{L}_{\mathrm{i}}\right)$. Specifically, to encode the differences in $y$ with volume loading:

$$
\mathrm{V}_{\mathrm{b}}=\left\{\begin{array}{l}
1 \text { if first volume loading } \\
0 \text { otherwise }
\end{array}\right.
$$

and

$$
\mathrm{V}_{\mathrm{c}}=\left\{\begin{array}{l}
1 \text { if second volume loading } \\
0 \text { otherwise }
\end{array}\right.
$$

and to encode differences due to direct ventricular interaction secondary to acute pressure loading by pulmonary artery constriction:

$$
C_{1}= \begin{cases}1 & \text { if first level of pulmonary artery constriction } \\ 0 & \text { otherwise }\end{cases}
$$

and

$$
C_{I I}=\left\{\begin{array}{l}
1 \text { if second level of pulmonary artery constriction } \\
0 \text { otherwise }
\end{array}\right.
$$

Finally, to allow for between-lamb differences, define the five dummy variables, $\mathrm{L}_{1}, \ldots, \mathrm{L}_{5}$,

$$
\mathrm{L}_{\mathrm{i}}=\left\{\begin{array}{l}
1 \text { if lamb i }(\mathrm{i} \leq 5) \\
-1 \text { if lamb } 6 \\
0 \text { otherwise. }
\end{array}\right.
$$

The coefficient associated with each dummy variable in the regression equation represents the change in $\mathrm{y}$ independently associated with each factor. These changes were considered statistically significantly different from zero based on a $t$ test for each coefficient when the associated $p$ was $<0.05$. We also tested whether these interventions affected the end-diastolic pressurevolume relationship by using end-diastolic pressure as the dependent variable and adding end-diastolic area as an independent variable. 


\section{RESULTS}

Basic hemodynamic results. The basic hemodynamic results are shown in Table 1. Volume loading and pulmonary artery constriction increased maximum right ventricular pressure significantly. Heart rate did not change. Volume loading increased LVEDP significantly and shifted the end-diastolic pressure-area curve upward but did not affect the other variables. The two levels of pulmonary artery constriction decreased maximum left ventricular pressure significantly. Similarly, LVEDP decreased during pulmonary artery constriction as did $\mathrm{LV} \mathrm{dP} / \mathrm{dt}_{\max }$. These results are similar to our previous findings (22).

Systolic pressure-area loops. Figure 1 presents the hemodynamic responses to one level of pulmonary artery constriction in one lamb. Constricting the pulmonary artery increased right ventricular systolic pressure and reduced left ventricular systolic pressure. Both left ventricular dimensions fell, but the dimension changes during systole were maintained, so left ventricular stroke area (and aortic flow) did not change significantly with pulmonary artery constriction.

By transiently changing afterload, multiple end-systolic pressure-area points can be generated to determine the end-systolic elastance. (Note that the areas are based on external measurements and include myocardial mass.) The area intercept at zero ventricular pressure is an indication of the operating area (volume) range for the ventricle. It does not shift with changes in inotropic state (28). Figure $2 A$ represents a series of pressure-area loops generated under baseline load conditions. Figure $2 B$ represents a similar series under the same loading conditions in the same lamb when the first level of pulmonary artery constriction was imposed. Figure $2 C$ shows these two series of loops superimposed to reveal that the slope of the end-systolic pressure-area relationship is similar in these two different right ventricular loading conditions, whereas the area intercept shifts to the left with increased right ventricular afterload. The stroke areas (analogous to stroke volume) did not change.

Configurational changes. Table 1 addresses the configurational changes in response to volume loading or pulmonary artery constriction. Volume loading had limited effects on both anterior-posterior and septal-free wall dimensions at end diastole and end systole. Pulmonary artery constriction had minimal effects on left ventricular anterior-posterior dimension, but significantly decreased the septal-free wall dimension at both end diastole and end systole. Thus, increasing right ventricular afterload decreases left ventricular end-diastolic area.

The changes in area in response to volume loading and right ventricular afterload are shown in Table 1. The major changes of interest are that both end-diastolic and end-systolic areas decreased significantly in the presence of pulmonary artery constriction, but stroke area did not change significantly. As a result, cardiac output, which equals the product of stroke area and heart rate, did not change significantly.

Table 1 shows the changes in $E_{\max }$ and $A_{d}$. $E_{\max }$ does not change significantly in the presence of volume loading or pulmonary artery constriction. However, $A_{d}$ decreases significantly with pulmonary artery constriction. These results combine to indicate that the pulmonary artery constriction reduced the operating volume of the left ventricle without changing its inotropic state.

\section{DISCUSSION}

We hypothesized that acute pulmonary hypertension in a neonatal animal model may alter left ventricular performance by altering its contractility, configuration, or both. These experiments demonstrate that left ventricular configuration, and not contractility, changes in response to increases in right ventricular afterload.

Mechanically increased right ventricular afterload decreased LVEDP and $\mathrm{LV} \mathrm{dP} / \mathrm{dt}_{\max }$, which could both be related to changes in preload. It also reduced the septal-free wall dimensions at both end systole and end diastole with no significant changes in anterior-posterior dimensions. Both end-systolic and end-diastolic areas decreased so that stroke area and cardiac output were maintained. $A_{d}$ decreased, suggesting that the operating range of areas (or volumes) of these ventricles in the presence of increased right ventricular afterload decreased. Right ventricular afterload altered left ventricular configuration, particularly in the septalfree wall dimension. Based on the end-systolic pressure-volume relationship, however, changes in right ventricular afterload did

Table 1. Responses to changes in loading conditions*

\begin{tabular}{|c|c|c|c|c|c|c|}
\hline Variable & Baseline & $\mathrm{Vol} \mathrm{B}$ & Vol C & Con I & Con II & $R^{2}$ \\
\hline \multicolumn{7}{|l|}{ Hemodynamic results } \\
\hline $\mathrm{RVP}_{\max }(\mathrm{mm} \mathrm{Hg})$ & $39.2 \pm 2.5$ & $6.5 \pm 3 \dagger$ & $9.2 \pm 3+$ & $18.7 \pm 3 \dagger$ & $29.9 \pm 3 \dagger$ & 0.83 \\
\hline HR (bpm) & $193.7 \pm 7$ & $15.4 \pm 8$ & $13.2 \pm 8$ & $5.2 \pm 7$ & $1.8 \pm 8.7$ & 0.52 \\
\hline $\mathrm{LVP}_{\max }(\mathrm{mm} \mathrm{Hg})$ & $106.5 \pm 5$ & $-2.5 \pm 6$ & $11.7 \pm 6$ & $-15.8 \pm 5 \dagger$ & $-10.7 \pm 6$ & 0.61 \\
\hline $\mathrm{dP} / \mathrm{dt}_{\max }(\mathrm{mm} \mathrm{Hg}) / \mathrm{s}$ & $3262.6 \pm 268$ & $-90.4 \pm 312$ & $572.0 \pm 312$ & $-580 \pm 274 \dagger$ & $-673.3 \pm 323 \dagger$ & 0.64 \\
\hline \multicolumn{7}{|l|}{ Dimensional results } \\
\hline $\mathrm{ED} \mathrm{SF}(\mathrm{mm})$ & $26.29 \pm 0.5$ & $1.04 \pm 0.5$ & $-0.27 \pm 0.5$ & $-2.31 \pm 0.5 \dagger$ & $-2.87 \pm 0.6^{\dagger}$ & 0.86 \\
\hline ES SF $(\mathrm{mm})$ & $24.88 \pm 0.3$ & $-0.52 \pm 0.4$ & $-0.47 \pm 0.4$ & $-2.19 \pm 0.3 \dagger$ & $-3.03 \pm 0.4 \dagger$ & 0.92 \\
\hline \multicolumn{7}{|l|}{ Area results } \\
\hline $\operatorname{EDA}\left(\mathrm{mm}^{2}\right)$ & $687.8 \pm 13$ & $-20.9 \pm 15$ & $7.1 \pm 15$ & $-64.4 \pm 13 \dagger$ & $-81.1 \pm 16 \dagger$ & 0.80 \\
\hline $\mathrm{ESA}\left(\mathrm{mm}^{2}\right)$ & $621.9 \pm 8$ & $-11.1 \pm 10$ & $17.9 \pm 10$ & $-52.8 \pm 9 \dagger$ & $-74.9 \pm 10^{\dagger}$ & 0.90 \\
\hline $\mathrm{SA}\left(\mathrm{mm}^{2}\right)$ & $65.8 \pm 7$ & $9.9 \pm 8$ & $-10.9 \pm 8$ & $-11.5 \pm 7$ & $-6.2 \pm 9$ & 0.44 \\
\hline $\mathrm{A}_{\mathrm{d}}\left(\mathrm{mm}^{2}\right)$ & $498.6 \pm 13$ & $5.8 \pm 15$ & $13.1 \pm 15$ & $-39.2 \pm 13 \dagger$ & $-76.2 \pm 15 \dagger$ & 0.78 \\
\hline
\end{tabular}

* All changes are in absolute (not percentage) units. Vol B, second loading condition; Vol C, third loading condition; Con I, first level pulmonary artery constriction; Con II, second level pulmonary artery constriction; $R^{2}$, correlation coefficient; $\mathrm{RVP}_{\max }$, peak right ventricular pressure; HR. heart rate; $\mathrm{LVP}_{\max }$, peak left ventricular pressure; $\mathrm{dP} / \mathrm{dt}_{\max }$, maximum derivative left ventricular pressure; ED AP, end-diastolic anterior-posterior; ES AP, end-systolic anterior-posterior; ED SF, end-diastolic septal-free; ES SF, end-systolic septal-free; EDA, end-diastolic area; ESA, end-systolic area; SA, stroke area: CO, cardiac output.

$\dagger p<0.05$; dependent variables determined from multiple linear regression. Values are coefficient \pm SEM. $n=46$. 


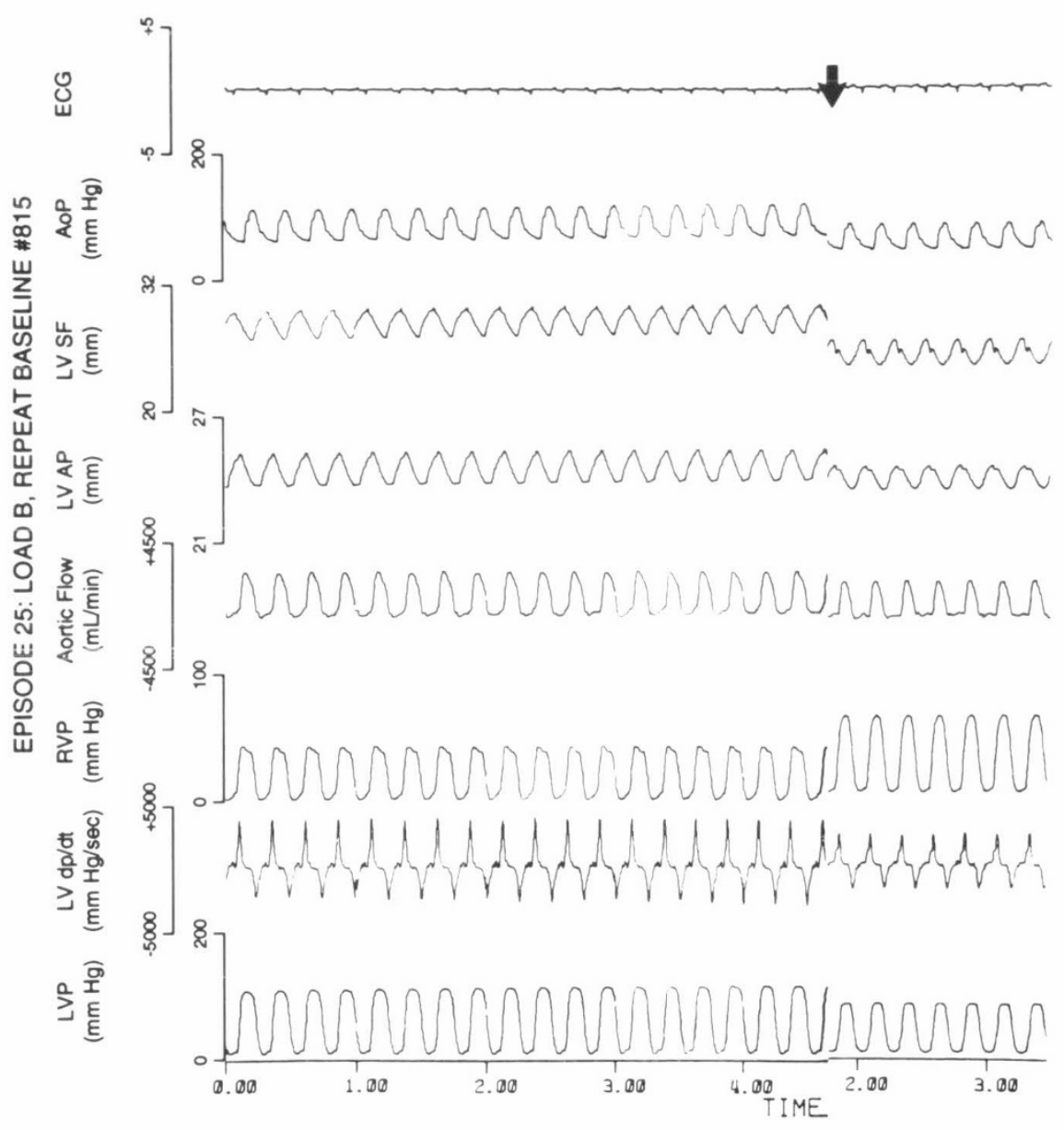

Fig. 1. Digitized tracings depicting the hemodynamic response before and after the first level of pulmonary artery constriction. In response to the constriction, right ventricular pressure $(R V P)$ increases, and left ventricular pressure $(L V P)$ and $\mathrm{LV} \mathrm{dP} / \mathrm{dt}$ decrease. The ventricular dimensions decrease during pulmonary artery constriction throughout the cardiac cycle, maintaining the stroke area. (Data from lamb 815 .) $L V A P$. left ventricular anterior-posterior; $L V S F$, left ventricular septal-free; $A O P$, aortic pressure.
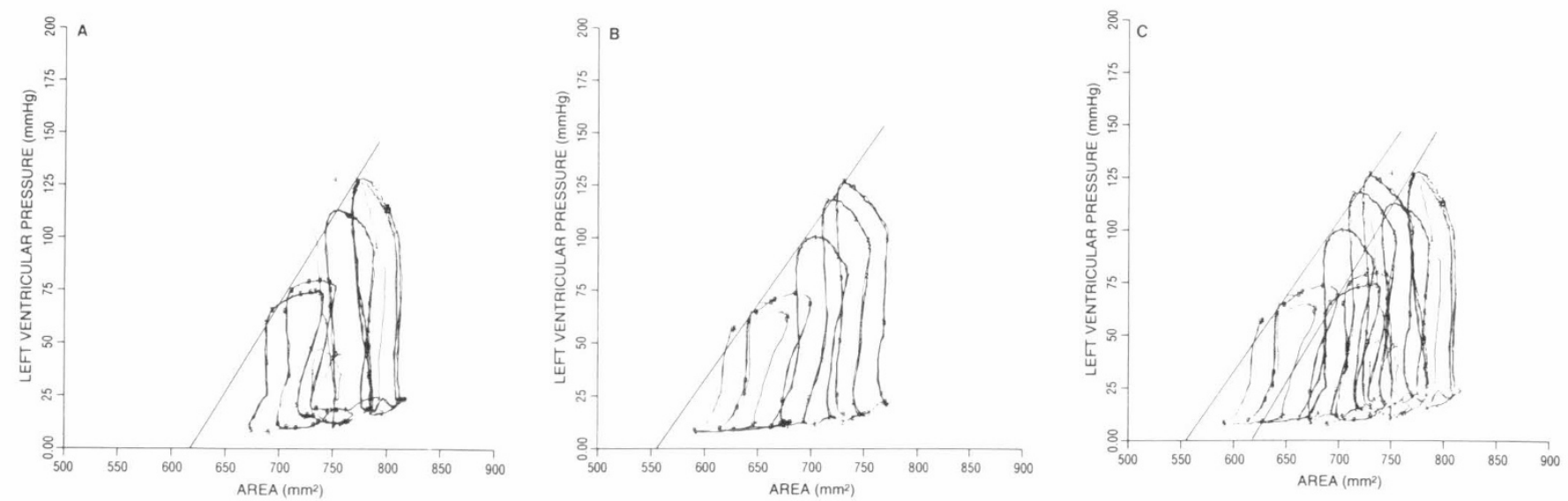

Fig. 2. A, A series of pressure-area loops recorded during brief, sustained aortic occlusions under baseline loading conditions. The $\mathrm{E}_{\max }$ represents the end-systolic elastance. $B$, A series of pressure-area loops recorded during brief, sustained aortic occlusions when the first level of pulmonary artery constriction was imposed under baseline loading conditions. $C$, The two series of pressure-area loops under baseline loading conditions with and without the first level of pulmonary artery constriction are superimposed. The maximum elastance, $E_{\max }$, does not change; however, the $A_{d}$ decreases in the presence of pulmonary artery constriction. (Data from lamb 816.)

not alter left ventricular contractility. Thus, in spite of configurational changes, normal left ventricular systolic function was maintained without a change in inotropic state. To maintain stroke area and cardiac output in the presence of a shift of the area intercept and change in configuration, the left ventricle would have to increase its ejection fraction. This result is con- sistent with findings reported by Olsen et al. (21) and Feneley et al. (29) in adult dogs.

The fact that the ventricle operates at a lower $A_{d}$ after pulmonary artery constriction than before constriction is entirely predictable based on simple geometry. Because the end-systolic force-length relationship is a property of the myocardial fiber, 
anything that alters the relationship between fiber length and area will alter the force-area relationship. Contained area is maximal for a circular shape. For any given circumference, the contained area will fall if the chamber becomes noncircular. This is a mechanical, geometric effect.

Human adults as well as adult animal models with acute pulmonary hypertension exhibit impaired left ventricular performance $(15-17,30,31)$. Changes in left ventricular geometry or configuration rather than contractility appear to be responsible for this impaired performance, with the effects being primarily on the left ventricular diastolic pressure-volume relationship rather than on left ventricular systolic function $(21,32)$.

Limitations of this study. We used the product of two perpendicular left ventricular equatorial dimensions as a substitute for left ventricular volume. We used these dimensions because we anticipated greater changes in the septal-free wall dimension than in the anterior-posterior dimension because of direct ventricular interaction accompanying the increase in right ventricular afterload $(21,33-35)$. We confirmed more striking changes in the septal-free wall dimension, as have other investigators $(21,33)$. The base-apex dimension, which makes a relatively minor contribution to changes in volume compared with the minor axis area, would be essential to assess absolute volume, but its exciusion from our measurements does not impede us from addressing the relative effects of increased right ventricular afterload on global left ventricular configuration and contractility (33). We did not measure and subtract myocardial area to assess chamber area. Because the myocardial area should be constant or change minimally under the conditions in this study, little information of value would be added by measuring the ventricular axis in terms of the underlying hypothesis being tested (33).

We used moderate changes in left ventricular afterload to generate multiple pressure-area loops. This procedure may result in baroreceptor reflexes (8), which may change end-systolic elastance. To avoid such changes, we blocked these reflexes by sprinkling the vagal trunks with lidocaine, so that we could better define contractility changes associated with our interventions (36). Inotropic blockade was not used for two reasons. In one previous study (22), the effects of increased right ventricular afterload induced by either mechanical constriction of the main pulmonary artery or alveolar hypoxia on left ventricular function were compared. Significant decreases in systemic blood flow and $\mathrm{dP} / \mathrm{dt}_{\max }$ developed with no changes in heart rate or aortic blood pressure in the presence of mechanically increased right ventricular afterload. When the afterload was induced with alveolar hypoxia, these four variables increased. These increases could be prevented with $\beta$-adrenergic blockade. Because the lambs in this study were not hypoxemic and their heart rates did not increase in the presence of pulmonary artery constriction, an increase in inotropic background was unlikely. In another study (37), mechanically increased right ventricular afterload was induced by balloon distension of the left pulmonary artery resulting in small increases in systemic vascular resistance and mean aortic pressure. Although these increases could be prevented with $\alpha$-adrenergic blockade, blockade was not used in this study because the magnitude of the increases would be unlikely to alter left ventricular function and the site of the pulmonary artery constriction was proximal to the site of the stretch receptors responsible for changes in systemic vascular resistance (37).

We used $\bar{E}_{\max }$ as an index of contractility relatively independent of preload and afterload in neonates (8). In adult animals. there appears to be contractility-dependent curvilinearity to the end-systolic pressure-volume relationship (38). Thus, $\mathrm{A}_{\mathrm{d}}$ determined by extrapolating multiple end-systolic pressure-volume data may be shifted with changes in load with inotropic state (39.40). Teitel et al. (9), demonstrated that, although there may be some curvilinearity to the end-systolic pressure-volume relationship of neonates, this curvilinearity is small, so the linear points we used provide reasonable estimates of $E_{\max }$ and $A_{d}$ as measures of inotropic state and the operating area range of the ventricle.

Other methods have been proposed to obtain quantitative measures of inotropic state. A second method is the relationship between left ventricular stroke work and EDV at different EDV $(41,42)$; this linear relationship is reasonably independent of load and the slope changes in inotropic state. The stroke-workEDV relationship is essentially a restatement of the original Frank-Starling Law. This relationship is defined by plotting the areas of the loops in Figure 1 against the EDV volume of each beat. We did not find significant correlation between stroke work and end-diastolic area during intervention runs in our neonatal lambs. Finally, Little et al. $(43,44)$ proposed examining the relationship between $\mathrm{dP} / \mathrm{dt}_{\max }$ and EDV as a measure of inotropic state. This relationship is also reasonably linear, independent of loading, and has a slope that changes in response to inotropic agents. All three methods are thought to provide different views of the same phenomena: we do not know why the stroke work was not correlated with end-diastolic area in the neonatal lambs we studied.

Significance of our findings. Despite the relative structural and functional immaturity ( $1-4,6-9)$, only left ventricular diastolic function (pressure-volime rclationship) was affected by increases in right ventricular afterload without changes in left ventricular contractility. Thus, if the human neonatal heart is functionally similar to the heart of the ovine neonate, the impaired left ventricular systolic function observed in some infants with persistent pulmonary hypertension of the newborn may be due to altered preload mediated by mechanical ventricular interaction, without alterations in contractility.

Acknowledgment. The authors thank James Stoughton for his excellent technical assistance.

\section{REFERENCES}

Friedman WF 1973 The intrinsic properties of the developing heart. In: Friedman WF. Lesch M. Sonnenblick EH (eds) Neonatal Heart Disease. Grune and Stratton. New York. pp 21-49

Friedman WF 1972 The intrinsic physiologic properties of the developing heart. Prog Cardiovasc Dis 15:87-111

3. Berman Jr W. Musselman J 1979 Myocardial performance in the newborn lamb. Am J Physiol 237:H66-H70

4. Riemenschneider TA. Brenner RA. Mason DT 1981 Maturational changes in myocardial contractile state of newborn lambs. Pediatr Res 15:349-356

Kirkpatrick SE, Pitlick PT, Naliboff J. Friedman WF 1976 Frank-Starling relationship as an important determinant of fetal cardiac output. Am J Physiol 231:495-500

6. Hawkins J. Van Hare GF. Schmidt KG. Rudolph AM 1989 Effects of increasing afterload on left ventricular output in fetal lambs. Circ Res 65:127-134

Van Hare GF. Hawkins JA. Schmidt KG. Rudolph AM 1990 The effects of increasing mean arterial pressure on left ventricular output in newborn lambs. Circ Res 67:78-83

8. Teitel DF. Sidi D. Chin T. Brett C. Heymann MA. Rudolph AM 1985 Developmental changes in myocardial contractile reserve in the lamb. Pediatr Res 19:948-955

9. Teitel DF. Klautz R. Steendijk P. Van Der Velde ET, Van Bel F. Baan J 1991 The end-systolic pressure-volume relationship in the newborn lamb: effects of loading and inotropic interventions. Pediatr Res 29:473-482

10. Minczak BM. Wolfson MR. Santamore WP. Shaffer TH 1988 Developmental changes in diastolic ventricular interaction. Pediatr Res 23:466-469

11. Milstein JM. Goetzman BW, Riemenschneider TA. Wennberg RP 1979 Increased systemic vascular resistance in neonates with pulmonary hypertension. Am J Cardiol 44:1159-1162

12. Riemenschneider TA. Nielson HC. Ruttenberg HD, Jaffe RB 1976 Disturbances of the transitional circulation: spectrum of pulmonary hypertension and myocardial dysfunction. J Pediatr 89:622-625

13. Riggs T. Hirschfeld S. Fanaroff A. Liebman J. Fletcher, Meyer R. Bormuth C 1977 Persistence of fetal circulation syndrome: an echocardiographic study. J Pediatr 91:626-631

14. Rowe RD. Hoffman T 1972 Transient myocardial ischemia of the newborn infant: a form of severe cardiorespiratory distress in full-term infants. $J$ Pediatr 81:243-250

15. Zapol WM. Snider MT 1977 Pulmonary hypertension in severe acute respiratory failure. N Engl J Med 296:476-480

16. Baum GL. Schwartz A. Llamas R, Castillo C 1971 Left ventricular function in chronic obstructive lung disease. N Engl J Med 285:361-365 
17. Rao BS, Cohn KE. Eldridge FL. Hancock EW 1968 Left ventricular failure secondary to chronic pulmonary disease. Am J Med 45:229-241

18. Elzinga G, Van Grondelle R. Westerhof N. Van DenBos GC 1974 Ventricular interference. Am J Physiol 226:941-947

19. Elzinga G, Piene H, De Jong JP 1980 Left and right ventricular pump function and consequences of having two pumps in one heart. Circ Res 46:564-574

20. Glantz SA, Misbach GA, Moores WY. Mathey DG, Lekven J. Stowe DF. Parmley WM. Tyberg JV 1978 The pericardium substantially affects the left ventricular diastolic pressure-volume relationships in the dog. Circ Res 42:433-441

21. Olsen CO, Tyson GS, Maier GW, Spratt JA, Davis JW Rankin JS 1983 Dynamic ventricular interaction in the conscious dog. Circ Res 52:85-104

22. Milstein JM, Bennett SH 1987 Increased right ventricular afterload alters left ventricular function in newborn lambs. Am Heart J 114:369-377

23. Appleyard RF, Glantz SA 1990 Two dimensions describe left ventricular volume change during hemodynamic transients. Am J Physiol 258:H277$\mathrm{H} 284$

24. Slinker BK, Glantz SA 1986 End-systolic and end-diastolic ventricular interaction. Am J Physiol 251:H1062-H1075

25. Van Trigt P. Bauer BJ. Olsen CO. Rankin JS, Wechsler AS 1981 An improved transducer for measurement of cardiac dimensions and sonomicrometry. Am J Physiol 240:H664-H668

26. Minczak BM, Wolfson MR. Santamore WP. Shaffer TH 1990 Pericardial effects on diastolic ventricular interaction during development. Pediatr Res 27:547-551

27. Giantz SA, Slinker BK 1990 Primer of Applied Regression and Analysis of Variance. McGraw-Hill, New York, pp 390-400

28. Sagawa K 1978 The ventricular pressure-volume diagram revisited. Circ Res 43:677-687

29. Feneley MP, Olsen CO, Glower DD, Rankin JS 1989 Effect of acutely increased right ventricular afterload on work output from the left ventricle in conscious dogs. Circ Res 65:135-145

30. Kelly DT, Spotnitz HM, Beiser GD. Pierce JE. Epstein SE 1971 Effects of chronic right ventricular volume and pressure loading on left ventricular performance. Circulation 44:403-412

31. Stool EW. Mullins CB. Leshin SJ, Mitchell JH 1974 Dimensional changes of the left ventricle during acute pulmonary arterial hypertension in dogs. Am J Cardiol 33:868-875

32. Calvin JE. Baer RW. Glantz SA 1986 Pulmonary injury depresses cardiac systolic function through Starling mechanism. Am J Physiol 251:H722 $\mathrm{H} 733$

33. Slinker BK. Glantz SA 1985 The accuracy of inferring left ventricular volume from dimension depends on the frequency of information needed to answer a given question. Circ Res 56:161-174

34. Slinker BK. Chagas ACP. Glantz SA 1987 Chronic pressure overload hypertrophy decreases direct ventricular interaction. Am J Physiol 253:H347-H357

35. Sagawa K 1981 Editorial: the end-systolic pressure-volume relation of the ventricle: definition, modifications and clinical use. Circulation 63:1223 1227

36. Sagawa K. Maughan L, Suga H, Sunagawa K 1988 Cardiac Contraction and the Pressure-Volume Relationship. Oxford University Press, Oxford. UK pp 139-143

37. Milstein JM. Goetzman BW 1985 Effect of pulmonary artery constriction on systemic vascular resistance in newborn lambs. Am J Cardiol 56:681-684

38. Burkhoff D. Sugiura S. Yue DT. Sagawa K 1987 Contractility-dependent curvilinearity of end-systolic pressure-volume relations. Am J Physiol 252:H $1218-\mathrm{H} 1227$

39. van der Velde ET, Burkhoff D. Steendijk P, Karsdon J, Sagawa K, Baan J 1991 Nonlinearity and load sensitivity of end-systolic pressure-volume relation of canine left ventricle in vivo. Circulation 83:315-327

40. Kass DA, Beyar R. Lankford E. Heard M. Maughan WL. Sagawa K 1989 Influence of contractile state on curvilinearity of in situ end-svstolic pressurevolume relations. Circulation 79:167-178

41. Misbach GA. Glantz SA 1979 Changes in the diastolic pressure-diameter relation alter ventricular function curves. Am J Physiol 237:H644-H648

42. Glower DD. Spratt JA. Snow ND. Kabas JS, Davis JW. Olsen CO. Tyson GS Sabiston Jr DC. Rankin JS 1985 Linearity of the Frank-Starling relationship in the intact heart: the concept of preload recruitable stroke work. Circulation 71:994-1009

43. Little WC 1985 The left ventricular $\mathrm{dP} / \mathrm{dt}_{\max }$-end-diastolic volume relation in closed chest dogs. Circ Res 56:808-815

44. Little WC. Cheng C. Mumma M. Igarashi Y. Vinten-Johansen J, Johnston WE 1989 Comparison of measures of left ventricular contractile performance derived from pressure-volume loops in conscious dogs. Circulation 80:1378 1387 